\title{
Manuel Antonio y la vanguardia literaria gallega
}

\author{
CARMEN MEJÍA RUIZ
}

UNIVERSIDAD COMPLUTENSE DE MADRID

No podemos introducirnos en la vanguardia literaria gallega y mucho menos podemos hablar de la poética de Manuel Antonio sin hacer mención a la generación correspondiente. Debemos situarnos en los años veinte y no olvidar que son los años fundamentales en el ámbito cultural gallego, años en los que la literatura gallega y sus creadores buscan caminos nuevos para conseguir que las letras gallegas alcancen una meta: su universalización. Este afán de universalización lo promueven los hombres de A xeneración Nós; generación que se define por su homogeneidad ya que participa, como señala Arcadio López Casanova, de una nueva sensibilidad vital, de unos nuevos fundamentos estéticos ${ }^{1}$. Entre estos hombres hay narradores, estudiosos, músicos y pintores, y todos ellos desean conseguir para la cultura gallega lo anteriormente expuesto.

Serán los poetas jóvenes quienes romperán con la tradición literaria gallega, y con ellos se manifestarán los primeros signos de ruptura. En esta generación poética se incluyen varios poetas que nacen entre 1900 y 1901 , se deben mencionar a Luis Pimentel (1895), Manuel Antonio (1900), Manuel Luis Acuña (1900), Euxenio Montes (1900), Fermín Bouza Brey (1901), Amado Carballo (1901), Anxel Johan (1901), Augusto Casas (1906). Otros críticos has denominado a esta generación xeración de 1925 , y la tradicional denominación es la de novecentistas, pero hay que señalar que estas diferentes denominaciones no conllevan grandes diferencias y que sólo dependen del criterio que utilizan los distintos críticos.

Nos parece necesario plantear quién orienta a estos jóvenes en su andadura ideológica y estética. En este sentido, Arcadio López Casanova señala: $P a$ -

1 Lopez Casanova, A., Luis Pimentel e sombra do aire na herba, Vigo, Galaxia, 1990, p. 20. 
ra os mozos daqueles anos, Vicente Risco foi sen dúbida, pola súa curiosidade espiritual e o seu senso divulgador, didáctico, o home-guieiro por excelen$\mathrm{cia}^{2}$. Efectivamente, en la correspondencia de Manuel Antonio encontramos lo afirmado por Arcadio López Casanova. El 17 de febrero de 1920, Vicente Risco escribe a Manuel Antonio dándole su opinión acerca de algunos de sus poemas, le dice así:

Sigo con atención o labore seu. Ude. anda a buscar unha forma propia, y eso está ben $O$ que lle non poderia perdoar sería que buscase, torto ou direito. simplesmentes a orixinalidade (...) Sexa independente d' escolas e de novedades, $e$ siga o seu camiño con sinxeleza.

Góstame ben atopar a suas cousas cheas de novedade, anque nonas aprobaría todas, non polo seu valor, senon pola sua tendenza, enténdame ben ${ }^{3}$.

Lo que no sabemos es a qué poemas se refiere Risco, pero ya tenemos una prueba de que al gran ideólogo del nacionalismo gallego, la poesía de Manuel Antonio le interesaba, y lo animaba a seguir escribiendo desde su individualidad estética.

Siguiendo en esta línea, y teniendo en cuenta que Manuel Antonio sólo tiene veinte años por aquel entonces, hay otra carta, esta vez de Manuel Antonio a Vicente Risco, que nos parece interesante reproducir. Escribe Manuel Antonio así:

Sr. Risco:

Eu sei que é vostede persoa conecente d'os fundamentos teóricos das máis novas tendencias literarias. Teño intrés en poder xuzgar por min mesmo os derradeiros ismos. E sendo esto case imposibel n' unha aldea, a trasmán de todo movemento cultural, coidei axeitado molestal-o, e perdoe, pra lle facer istas preguntas:

Onde poderéi adquirir o Manifiesto futurista catalán, pubrigado fai pouco. y-o seu Libro Preludio a toda Estética futura?

Cales obras, e de quen, poderánme informar sintéticamente do que sexa futurismo, cubismo, dadaísmo, ultraismo, unanimismo, imaxinismo, etc.?

2 Ibídem.p. 26.

${ }^{3}$ Manoel Antonio, Correspondencia III, Vigo, Galaxia, 1979, p. 68. 
Que revistas dan produciós d'isa clás?

Que libros, e de quen, fan literatura d' isa?

E se a todo iso quixera engadir algún dato que coide comenente, medrará o intenso agradecemento a que ficarei obrigado pol-a sua respost ${ }^{4}$.

Esta carta data del 24 de septiembre de 1920, lo que nos pone delante de un joven inquieto, con deseos de conocer los movimientos vanguardistas y pide ayuda a la persona que mejor conoce los ismos, pero en el fondo se lo pide a Risco porque es el guía de esta generación de ruptura, es quien los apoya a seguir adelante. Otro dato importante de esta carta es el deseo de conocer el Manifiesto de Salvat Papasseit y nos preguntamos si Manuel Antonio ya estaría pensando hacer un Manifiesto.

Lo que corrobora que Vicente Risco es el guía de esta generación, se manifiesta en la respuesta que Risco da a la carta de Manuel Antonio, por supuesto que le da una amplia bibliografía sobre los ismos, pero lo más importante de esta carta es lo que piensa Risco de estos ismos, y lo que considera que se debe hacer en Galicia, dice así:

(...) Eu non son partidario de ningunha d'estas escolas. Fago poemas d'estos (...) Hoxe, os galegos, escribindo no noso idioma principiamos a nos abrir camiño no mundo, sen necesidá d'andar buscandolle cinco pés ô gato con ismo de ningunha clás. Mais como compre qu' esteamos enterados de todo, que non sexamos alleos ô mundo d'afora, por iso me teño dedicado a espallar isas cousas na nosa Terra (...) E conte que o que os extranxeiros han estimar mais en nós, ha ser o carauter nacional, o galegismo, o enxebrismo da nosa arte e da nosa literatura, pois iso é o que ha ter novedá pra eles, e o que eles se nós faguemos cousas boas chegarán a imitar (...)

Moi ben que queiramos faguer cousas novas -sempre dentro do noso- pro cando as fagamos, non sexan con as fan en Londres, nin en París, nin en ningures, senon coma nonas haxan feito ainda en ningunha parte do mundo $(\ldots)^{5}$.

Estos postulados ideológicos y estéticos resumen claramente lo que Risco consideraba necesario para la cultura gallega: no quedarse aislados y ser originales teniendo presente siempre el nacionalismo gallego, características que

\footnotetext{
4 Ibidem, p. 74.

5 Ibidem, pp. 76-77.
} 
están recogidas en el Manifiesto que Manuel Antonio junto a Alvaro Cebreiro publicarán en 1922.

Pero nos interesa destacar una frase que, quizá, haya pasado desapercibida: (...) Fago poemas d'estos (...) dice Risco al hablar de los ismos. Es decir, Risco tiene poemas publicados en A Nosa Terra que se relacionan con los ismos, por ejemplo el titulado $U \ldots$.. ju juuu..., poema futurista y si Risco hubiera seguido en esta línea hubiera podido ser - como observa Arcadio López Casanova- o poeta da ruptura primeira e transición entre a tradición dos novecentistas e a lírica nov $a^{6}$. Hecho importante porque no sólo es el guía de nuestros poetas jóvenes sino que inicia el camino de ruptura poética, aunque de forma ocasional.

Del Manifiesto se tienen noticias también en la correspondencia de Manuel Antonio. El 27 de diciembre de 1921, Manuel Antonio escribe e Alvaro Cebreiro en la que le dice que el Manifiesto está en xestación. As cousas que valen teñen que pasar pola preñez, coma a xente. (Qué escándalo! Estar preñado c'un manifiesto ${ }^{\dagger}$. En febrero del año siguiente Cebreiro escribe a Manuel Antonio y le dice que: o manifiesto urxe. Y el Manifiesto se publica en 1922, no mes de S. Xoan ${ }^{8}$.

Aunque la pregunta que vamos a formular parezca redundante, nos parece necesaria para hablar del rupturismo del Manifiesto ;Máis Alá! ¿Por qué aparecen los Manifiestos? Según Ríos Panisse:

Moitos movementos avangardistas deron á luz provocativos manifestos para chama-la atención sobre a súa opinión artística e principalmente sobre a persoa dos seus creadores, que buscaban fama e adeptos. O manifiesto constituía un tipo de propaganda barata e, moitas veces, a única que se podía permitir un autor novo que non contaba nin quería o apoio da cultura oficial, establecida, á que rexeitaba por caduca9.

A pesar de que el Manifiesto ;Máis Alá! pueda responder a la mencionada definición, hay que decir que para las letras gallegas tiene importancia no sólo por ser el único Manifiesto en gallego, sino porque encierra una serie de particularidades ${ }^{10}$. Ríos Panisse con respecto a esto señala:

\footnotetext{
6 Lopez Casanova, A., Op. cit., p. 26.

7 Manoel antonio, Op. cit., p. 137.

8 Ibidem, p. 174.

9 Ríos Panisse, M., «O rupturismo do manifesto ¡Máis Alá!», en Dorna, decembro 1989, p. 87.

10 Ibidem.
} 
En efecto xa no comezo se presenta non só co afán de orixinalidade que domina noutros, senón coa intención de protesta artística verbo da sumisión que sofre a cultura galega. Iso fai (...) que este manifesto sexa especial, peculiar, pois non presenta só unha aspiración artística de orixinalidade individual senón que se centra na busca de novos camiños pra a arte de Galicia, camiños independentes da situación lingüística real, adiantándose asi na arte a unha situación de lingua normalizada ${ }^{11}$.

El Manifiesto hace una crítica despiadada a los artistas vellos, a los ruralistas y a los devanceiros. Y en estos tres puntos, el Manifiesto implica una ruptura con As Irmandades y A Xeneración Nós. Todos se movían con el lema de La modernidad para la cultura gallega, pero los firmantes del ;Máis Alá! son más explícitos.

Con respecto a os vellos dicen: enterrar os vellos en vida, baixo a lousa inmobil da súa vulgaridade, pola acefalia que supón o desexo de definir co pasado a hora de hoxe ${ }^{12}$. Y utilizan un argumento galleguista que propugnan la selección artística, en contra de la práctica de amparar todo lo escrito en gallego que se venía ejerciendo por las Irmandades y Nós ${ }^{13}$. Por lo tanto se puede hablar de insumisión vanguardista en la literatura gallega frente a la generación anterior.

La búsqueda de una base cultural gallega hizo que surgieran escritores que sólo utilizasen la temática y la forma de la cultura rural. Para los firmantes de este Manifiesto a estos escritores había que eliminarlos porque $o$ voluntario castramento espiritual e colectivo que supón na Galicia a existencia do caciquismo da ignorancia, do renunciamento á vida e á dignidade cómpre anulalo antes que no terreo político-social no senso estético ${ }^{14}$. La Xeneración Nós tampoco coincide con este postulado, ya que se intentó contactar con los epígonos y presentarlos como maestros. En cuanto a los devanceiros Rosalía, Curros y Pondal son atacados con acidez en el Manifiesto, pero esto se justifica porque los jóvenes vanguardistas eran rupturistas con el pasado e innovadores, como se nos dice: Nós somos os novos galeguistas que propugnamos unha ruptura, múltiples camiños, a seguridade do triunfo pola evidencia da nosa orixinalidade e da nosa valía ${ }^{15}$. Con respecto al habla gallega nuestros vanguardistas están dispuestos a crear en gallego porque a nosa Fala é nosa. Pospol-a a outra calquera, é unha forma d'o suicidio ${ }^{16}$.

\footnotetext{
11 Ibidem.

12 Ibídem.

13 Ibidem, p. 88

14 Ibídem.

15 Ibídem, p. 91.

16 Ibídem.
} 
Por el resumen que acabamos de hacer de los puntos más críticos del Manifiesto se podría pensar que estaría abocado al fracaso y que sería rechazado por los galleguistas y los representantes del grupo Nós, ya que el Manifiesto implica una ruptura con sus postulados estéticos. Nada más alejado de la realidad que esta suposición. Recurrimos de nuevo a la correspondencia de Manuel Antonio donde encontramos las siguientes opiniones. Antón Villar Ponte, escribe el 17 de abril de 1922 a Manuel Antonio diciéndole: Limos e relímol-o seu manifesto. A min paréceme insuperabel. Coido que non precisa nin mais engadegas nin ningunha chatadura ${ }^{17}$. Por otra parte Castelao también escribe a Manuel Antonio una vez leído el Manifiesto y le dice: Eu atopo moi ben o manifesto, moi ben, moi ben. Nin seguir retratando co-a inconsciencia d'unha máquina as cousas da Natureza nin sacar as cousas da cabeza como as arañas o fío do cú. Na interpretación debe estal-o noso cuño persoal ${ }^{18}$.

Es evidente que esta aceptación del Manifiesto supone el entendimiento de que hacían falta cosas nuevas que despertasen el ánimo de los jóvenes para lograr su aportación y su ayuda. Al menos de esta forma lo entendemos nosotros, y creemos que se lleva a cabo, por ejemplo con la aparición de las revistas de vanguardia Alfar en La Coruña y Ronsel en Lugo, entre otras. Además, aparecerán los libros que serán la muestra de la renovación y que supondrán la ruptura poética. Entre ellos se encuentran De catro a catro (1928) de Manuel Antonio, Proel (1927) de Amado Carballo, Nao senlleira (1932) de Bouza Brey, o Fírgoas (1933) de Manuel Luis Acuña.

Hablar del libro de Manuel Antonio De catro a catro en líneas generales es una tarea complicada si no imposible. De todas formas intentaremos dar las pautas principales siguiendo a Arcadio López Casanova, que desde nuestro punto de vista es quien mejor ha sabido entender a Manuel Antonio, cosa nada fácil ya que De catro a catro se caracteriza por su complejidad y hermetismo. Se ha hablado del creacionismo de Manuel Antonio y de la temática marinera que caracterizan a este libro. Esto sólo son meras apariencias. El libro nos muestra un viaje por el mar, y responde al diario que el poeta hace a bordo de la travesía, por ello el primer poema se titula Intencións y el último Adeus. Pero este viaje es, según Arcadio López Casanova, el abandono del mundo conocido, familiar y protector y, posteriormente, un regreso una vez cumplida la travesía. Este viaje representa para el actor-sujeto unas experiencias, unos descubrimientos, que tienen lugar en un mundo nuevo, desconocido. Este esquema corresponde a una estructura mítica; se trata de la aventura del héroe, representación de un viaje iniciático siempre con esas tres partes (abandono, aventura, regreso). Esta estructura mítica no es más que una forma

17 Manoel antonio, op. cit. sup., p. 164.

18 Ibidem, p. 181. 
de visualizar una aventura interior del actor-sujeto: es decir, una experiencia espiritual que el yo ha vivido y que ha tenido como consecuencia una transformación ${ }^{19}$. Aquí está la clave de ese viaje iniciático. Esta estructura mítica se visualiza a través de los símbolos, que si el lector no llega a captar nunca podrá entender los poemas de De catro a catro, libro hermético y complejo como hemos dicho anteriormente.

De todas formas hay que añadir que Manuel Antonio es un poeta que muere en 1930 y que su poesía y su ruptura poética se quedan en la aventura iniciática, otra cosa hubiera sido si Manuel Antonio hubiera vivido el tiempo necesario para dejar una obra poética de madurez.

Deseamos, antes de acabar con esta conferencia, aludir a otra de las peculiaridades de la poesía de Manuel Antonio. La poética de Manuel Antonio debe algo a los ismos vanguardistas, fundamentalmente al creacionismo. Ya el propio Manuel Antonio en El prólogo dun libro de poemas que ninguén escribeu reconoce su deuda a los diferentes movimientos de la vanguardia; ahora bien no se debe olvidar que la poesía de Manuel Antonio se aparta en ocasiones, y concretamente en De catro a catro, del esquema vanguardista. Como observa C. L. Bernárdez es o carácter unitario do poemario e a anulación do distanciamento entre o obxecto poético e o suxeito lírico, sendo a paisaxe, en moitas ocasións, reflexo da sentimentalidade do poeta ${ }^{20}$, característica que hace de la obra de Manuel Antonio un libro peculiar y, sobre todo, un libro que rompe con lo anterior y abre nuevos caminos en la poesía gallega, aportando las novedades existentes en el momento pero, fundamentalmente, innovando desde una perspectiva individual y humana. Sus poemas Intencións y Adeus a los que ya hemos hecho referencia ejemplifican lo expuesto.

Unos versos de ambos poemas hablan por sí mismos:

$$
\begin{aligned}
& \text { (...) } \\
& \text { Inventaremos frustradas descobertas } \\
& \text { a barlovento d'os horizontes } \\
& \text { pra acelerar os abolidos corazóns } \\
& \text { d'os nosos veleiros defraudados. }
\end{aligned}
$$

19 López Casanova, A., Op. cit. sup., pp. 32-33.

20 Bernardez, C. L., De catro a catro de Mamuel Antonio (Guías de lectura), Vilaboa (Pontevedra), Edics. do Cumio, 1991, p. 69. 
(...)

E cazaremol-a vela

sobre o torso rebelde d'as tormentas

pra trincar a escota d'unha ilusión.

(Intencións)

Es el comienzo del viaje, la búsqueda de los descubrimientos, de algo nuevo, la búsqueda, en definitiva, de la ilusión. El poeta desea ardientemente descubrir la ilusión a través de lo desconocido.

Y tras el viaje, esa búsqueda de lo desconocido, esa meta de alcanzar la ilusión en su viaje por Mar, llega el retorno y el desdoblamiento del yo. Esa despedida a algo que supuso una búsqueda interna de la ilusión desconocida y ansiada y el regreso a lo conocido, a lo de siempre, pero con una transformación íntima.

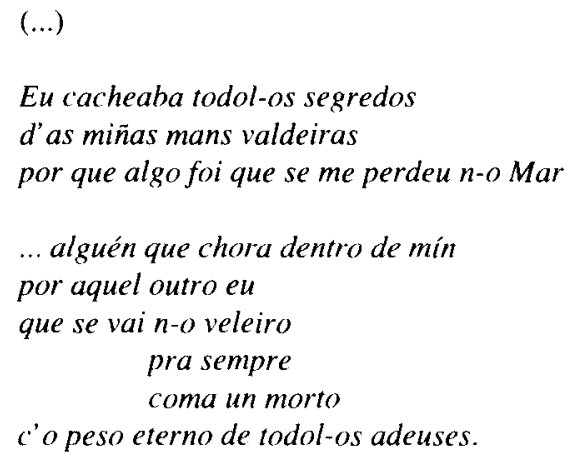

Desde esta perspectiva hay que reiterar que la poética de Manuel Antonio se aparta de los contenidos vanguardistas y es una poética innovadora y personal; y por ello, porque rompe, se debe considerar vanguardista en la literatura gallega. 